\title{
التشغيل العشوائي والفساد المالي والاداري
}

دراسة في جدلية العلاقة بينها

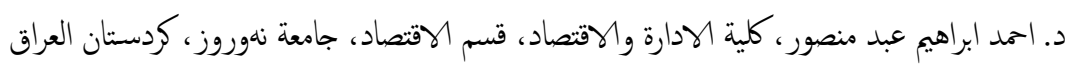

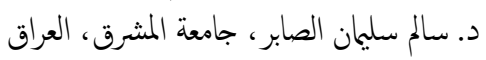

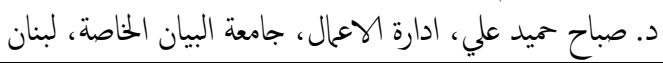

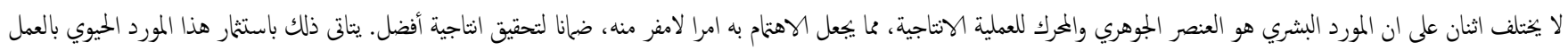

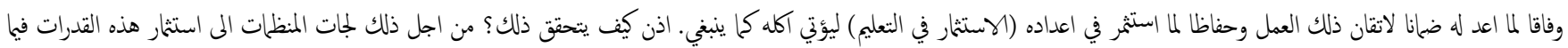

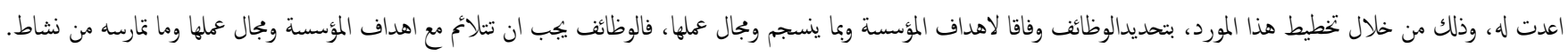

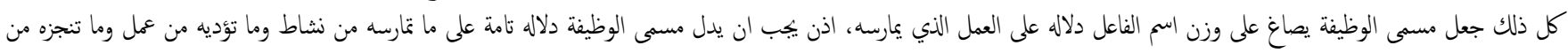

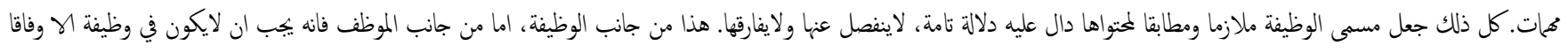

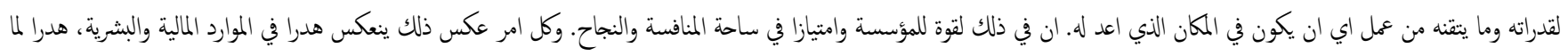

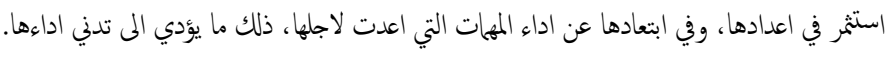

الكلمات المفتاحية: التشغيل العشوائي، الفساد الاداري، الفساد المالي.

1 . تمهيد

استثمر في اعدادها، وفي ابتعادها عن اداء المهات التي اعدت لاجلها ، ذلك ما

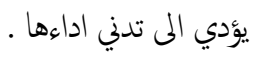

لكن النظر في الواقع يظهر غير ذلك فسميات الوظائف لا تعكس محتواها ، ولا الافراد يعملون في المواقع التي لا تتوافق مع تخصصاتهم ، وان ما يتقاضونه من اجر

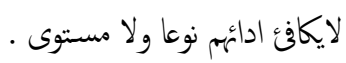
ما تقدم يظهر فسادا كبيرا متراكبا يتجسد في: - - مدرا في الاستثمار في التعليم - - معطيلا للطاقة الانتاجية ( هدرا في الموارد البشرية )

$$
\text { - }
$$

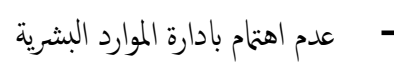

- - جمل المسوؤين عن ذلك في وزارة المالية المسوؤل عن صحة الملاك

$$
\text { وحقيقته }
$$

- ملاكا لايعكس الوظائف الحتيقية التي يؤديها الافراد

- - وظائفا مصاغة لما يوافق مؤهلات الفرد وما يحقق له افضل عوائد ، لاكما يوافق المؤسسة ويحافظ على مواردها ، ويرفع كفاءة اداءها .
لا يختلف اثنان على ان المورد البشري هو العنصر الجوهري والمرك للعملية الانتاجية، مما يجعل الاهتمام به امرا لامفر منه، ضانا لتحقيق انتاجية افضل. يتاتى ذلك باستثمار هذا المورد الحيوي بالعمل وفاقا لما اعد له ضهانا لاتقان ذلك العمل وحفاظا لما استثمر في اعداده (الاستثمار في التعليم) ليؤتي اكله كما ينبغي. اذن كيف يتحقق ذلك ؟ من اجل ذلك لجات المنظات المى استثخار هذه القدرات فيا اعدت له، وذلك من خلال تخطيط هذا المورد، بتحديدالوظائف وفاقا لاهداف المؤسسة وبما ينسجم و مجال عملها, فالوظائف يجب ان تتلائم مع اهداف المؤسسة و مجال عملها و ما تمارسه من نشاط.كل ذلك جعل مسمى الوظيفة يصاغ على وزن اسم الفاعل دلاله على العمل الذي يمارسه، اذن يجب ان يدل مسىى الوظيفة دلاله تامة على ما تمارسه من نشاط وما تؤديه من عمل وما تنجزه من مهات. كل ذلك جعل مسمى الوظيفة ملازما ومطابقا لمتواها دال عليه دلالة تامة، لاينفصل عها ولايفارقها ـ هذا من جانب الوظيفة، اما من جانب الموظف فانه يجب ان لايكون في وظيفة الح وفاقا لقدراته وما يتقنه من عمل اي ان يكون في المكان الذي اعد له. ان في ذلك لقوة للمؤسسة وامتيازا في ساحة المنافسة والنجاح. وكل امر عكس ذلك ينعكس هدرا في الموارد المالية والبشرية ، هدرا لما 


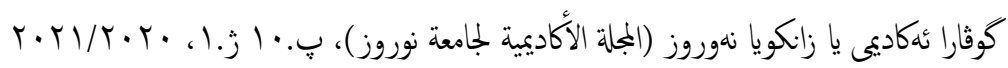

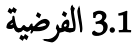

تحتيقا لنالك يتجه البحث لاختبار الفرضية التالية : ان هناك عدم توافق وعدم انسجام بين الوظائف ومجال عمل المؤسسة وبين الوظائف والموظفين ، فضلا عن ان الرواتب غير مكافئة للاداء

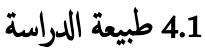

الدراسة تحليلية تتجه نحو تشخيص الظاهرة وبيان خطرها ، وطرح المعالجات التي قد تتجاوزها وتقضي عليها وتحد منها من خلال : - تهيد نظري بهي الاساس الفكري للتحليل .

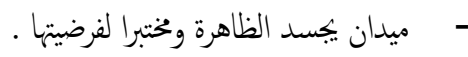

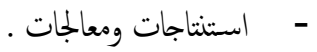

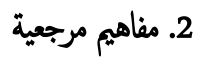
توضح هذه الفقرة بعضا من المفاهيم والمصطلحات التي سترد في البحث: 1.2

هي التشكيل التنظيي الادنى في اية مؤسسة. وهي البنة الاساس للاداء والوحدة الجوهرية فيه، تتضمن مجموعة من المهات والمسؤوليات والواجبات والصلاحيات التي تتصف بالتجانس والتكمل باتجاه تحقيق الهمداف التي استحدثت الوظيفة لتحتيقها، ولها اسم ( عنوان الوظيفة ) مشتق من طبيعة عملها وموقعها في المؤسسة يفصح عن محتواها ولا ينفصم عنه . يستلزم اداءها توافر شروط ومواصفات في من يشغلها على اساس هذه المهات والواجبات ودرجة صعوبة اداءها والظروف التي تؤدى بها تتحدد الاجراءات والراتب الذي تستحقه ( قيمة (www. Business Dictionary 2016,P:1-4) . ( )

2.2 مستويات الكاداء ( هرم الاداء ) يقصد به مستويات الوظائف التي تتضمنها المهة الواحدة ، والتي يتكامل اداءها مع بعضها البعض مثلا وظيفة الحسابات تتكون من عدد من المستويات الادائية : (كاتب حسابات، م. محاسب، محاسب، محاسب اقدم ..... ) فكل وظيفة من هذه الوظائف تمثل مستوى ادائيا معينا ، يتطلب توافر مواصفات محددة في من يشغلها وعلى اساس مستوى الاداء تتحدد الدرجة المالية والوظيفية لكل وظيفة كذلك هنالك هن تؤدى بمستوى اداء واحد مثل سائق، مصور، معلم، مدرس، كاتب طابعة اي ليس لها مستويات ادائية متدرجة هيكل الوظائف. ( سالم

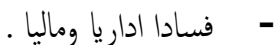

لقد حددت هذه المسألة البحثية من خلال معايشة الباحثين والعمل في

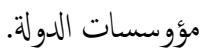

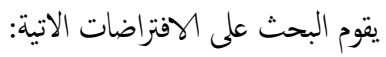
- الوظائف تعكس نوع وطبيعة المهات التي تقوم بها . - - مسميات الوظائف تتوافق ومهاتها وواجباتها .

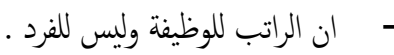
- - ان موازنة الرواتب يجب ان تكافي تكافٔ موازنة الحاء (اي كمية الوداء

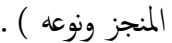

- - ان الوظائف الفنية هي التي تتجه نحو تحقيق الاهداف الحقيقية التي تسعى

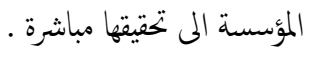

- - تطابق الاهرام الثلاثة : هرم الوظائف ، هرم الرواتب وهرم الموارد

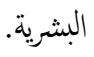

- ان عدم ادراك هذه المعظلة والتصدي لها والعمل على حلها وتجاوزها يشكل خللا كبيرا يعكس هدرا لموارد المجتم.

1.1

تبرز اهمية الموضوع من خلال توجيه الانظار المى مسالة تتجسد في توافق الاهرام الثلاثة ، فضلا عن انها تتجه نخو تنبيه المسوؤلين الى ضرورة الاهتمام في اسناد المهات الى اصحابها لا الى الاختيار العشوائي واسناد المناصب الى من لايستحقها ولا يكون كفؤأ لها الامر الذي ينعكس تدنيا في كناية الاستخدام وهدرا في الموارد المالية وتعطيلا للطاقات البشرية.

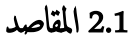

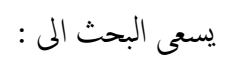
- - - - كثف هذه الظاهرة وتحديد سلتها .

- بيان درجة ومستوى الخطر الذي يتعرض له المجتع بسبها (هدر موارد

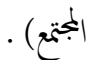
- - متزاح السبل التي قد تحد منها وتوابهمها. 


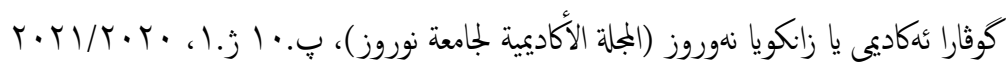

تترتب هذه الوظائف في مجموعات بمستويات مختلفة ومتباينة متدرجة ومشكلنا

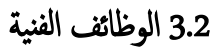

هرما ، يبدأ بوظائف عدة وينتهي بوظيفة واحدة على رأس الهرم ، هذا الهرم هي تلك الوظائف الاساس للمؤسسة التي تتصل بالنشاط العملياتي مباشرة يوضح المستويات الاشرافية للوظائف .كل مستوى منه يمثل صعوبة الوظيفة والذي يرتبط مباشرة بتحقيق الاهداف الجوهرية للمؤسسة, فهي الوظائف التي

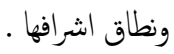
بعامة فان هيكل الوظائف يشمل جميع الوظائف التي تتتاج الهيا المؤسسة

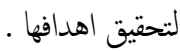
تحدد السمة الاساس للهيكل الوظيفي للمؤسسة، فالمؤسسة الصناعية تتسم طبيعة عملها بالتخصص الهندسي مثلا هذا يعني ان سمة معظم وظائهها ذات طبيعة هندسية، كذا المؤسسة التعليمية، يجب ان تكون وظائنها الاساس اتخذ البحث احدى مؤسسات التعليم العالي والبحث العلمي انموذجا لمؤسسات الدولة ( جامعة الهربين ) حقلا للدراسة واختبار فرضياتها .

(الفنية) ذات سمة تعليمة، وهكذا اية مؤسسة، فأن وظائنها الفنية تشتق من طبيعة عملها. هذه السمة يلزم ان تكون الغالبة لوظائف المؤسسة بعامه، ذلك ان الوظائف الفنية تعكس طبيعة النشاط المساس للمؤسسة ( سالم، 1999، ص:

\subsubsection{1الانسام بين هيكل الوظائف وانشطة المؤسسة الأساس}

تعد اهداف المؤسسة المرتكز الاساس الني تشتق منه انشطة المؤسسة الجوهرية ( النشاط الفني او العملياتي )لالني يرتكز عليه تحقيق الاهداف ، والانشطة

المساعدة والانشطة الفرعية وصولا الى ادنى وحدة تنظيمة ( الوظيفة ) . عليه فالنشاط العملياتي ( الفني) في المؤسسة يختلف باختلاف اهدافها ـ أما الانشطة المساعدة فنكاد لا تختلف فيا بين المؤسسات تبعا لاختلاف اهدافها الجوهرية مثل( الصيانة ، الخدمات ، الموارد البشرية ،..... ) التي تساند النشاط

تاسيسا يجوز القول بان الوظائف الفنية هي تاك الوظائف التي تتصل بمجال العمل الاساس للمؤسسة ـ فني المؤسسة التعليمة ( الجامعات ) الوظائف الفنية تتجسد بالنشاط الندريسي ( أستاذ مساعد، أستاذ مشارك ،أستاذ ....وما يساندها من وظائف تتطلهيا سير العملية التعلمية ). بفرض ذلك ان تشتق مسميات الوظائف الفنية من صميم العملية التعليمة وطبيعتها وتتناغٍ معها ، اي ان مسمى الوظائف يعكس طبيعة ومجال العمل . تاسيسا فان اي مخالفة لذلك تعد فسادا اداريا لكن ذالك لم يكن فسادا اداريا فسب بل ينعكس فسادا ماليا، (اي ان كل فساد اداري كهذا ينعكس فسادا

ان لحظ الواقع يظهر فوضى لاحد لها وتصرفا غير مسؤَل وعدم التزام بالاظظمة والقوانين والتعليمات النافذة لجهل وعدم معرفة قاعدة وقيادة .ذلك ان شغل الوظائف في التشكيلات لايقوم على الخبرة والدراية وتولية الكفؤ . فقد اظهرت معاينة الملاك ان معظم الوظائف التي يتضمنها عدألوظائف الندريسية منها لا تعطي انطباعا عن ان الملاك هو للمؤسسة التعليمة. فعلى سبيل 


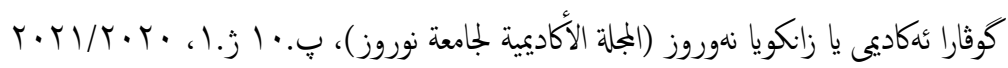

ومهمات وواجبات ومسؤوليات ـ لقد تبين في الفقرة السابقة ان الوظائف النوعية ترتبط بمجال عمل المؤوسسة ارتباطا وثيقا ، اذ تتزكز فيها الوظائف ذات الطبيعة المتخصصة بمجال عملها. ان هذه العلاقة تنطبق ايظا على الوظائف في التشكيلات الفرعية في المؤوسسة ، اذ تتركز الوظائف النوعية فيها ، فالوظائف الخخزية في الخخازن والوظائف الحسابية في الحسابات ، الوظائف التدقيقية في التدقيق وهكذا الحال لبقية الوظائف ـ ان هذا الربط ناجم عن الطبيعة التخصصية اللتشكيلات الادارية ووظائنها ـ وفي الجدول الاتي ايضاح لذلك.

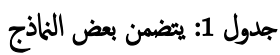

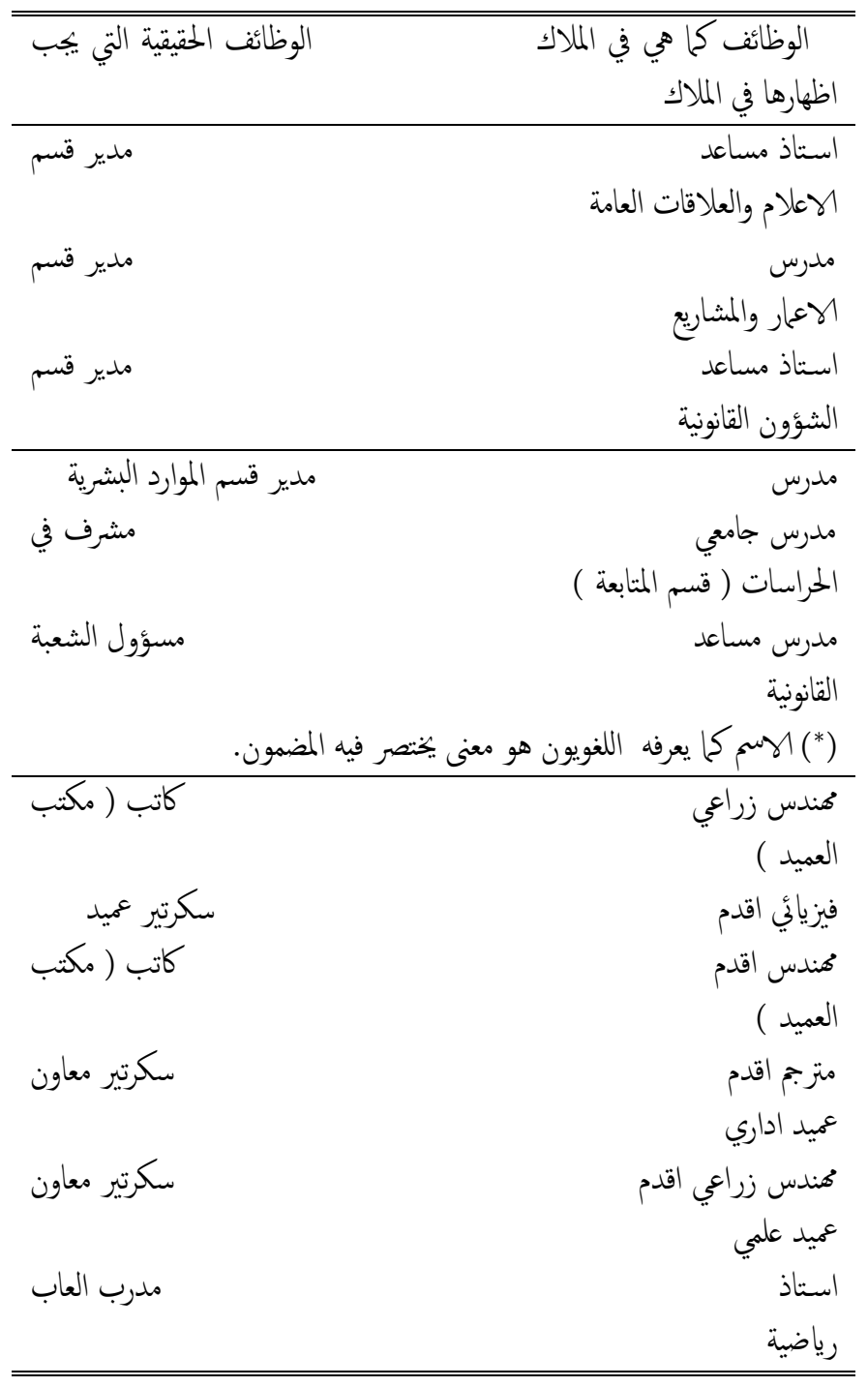

ان ما يوضحه الجدول ينطبق على معظم الوظائف ان لم يكن جميعها.فيا تقدم دلالة على فوضى التشغيل والتي تؤشر فسادا في اتجاهين ، مرتبات عالية مقابل أداء لايتوافق مع مستواها التاهيلي ، وهدرا في الموارد البشرية ( تعطيل للطاقات )

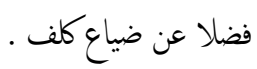

المثال لا الحصر تجد الوظائف : طبيب استشاري، صيدلي استشاري، طبيب اختصاص، رئيس صيادلة اقدم، رئيس ممرضين، مرض جامعي اقدم، رئيس

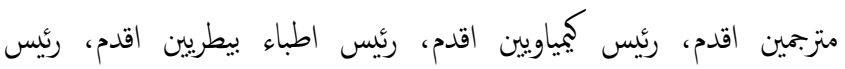
بايولوجيين ، معاون طبي، رئيس معاون طبي اقدم ، رئيس فيزياويين، رئيس هُندسين زراعيين، مبروج ، محلل انظمة، رئيس حرفين اقدم .... هذه الوظائف عينة من فيض ومشتقاتها م. بيولوجي ، بيولوجي هذه الوظائف لا تنسجم والعملية التعليمة فان كانوا مساعدين في العملية النعلمية فيكون عملهم في المختبرات بمساعدة من المدرس المساعد (استحدثت هذه الوظيفة لتحل محل وظيفة المعيد). لرب من يثيرتساؤلا ماهي اسباب ذلك ؟، لعل من اهم الاسباب التي عبثت بملاكات الجامعات هو الحصول على الخصصات التي يستحقها من يشغل هذه الوظائف اذ بعد ان صدرت القوانين في سبعينيات القرن الماضي التي قضت بمنح مخصصات هنية لمن يعمل في هذه الوظائف (وليس العنوانات ), ان هذا يؤشر خلا فادها ويحمل موازنة الدولة اعباء مالية كبرى ، فضلا عن ذلك يؤشر التسيب في ادارات الدولة المسؤولة عن مثابعة ذلك الوزارات ووزارة المالية بالتخصيص لانها المسؤلة المباشرة عن الموازنة والملاك ، فضلا عن التعيين بحسب هوى المسؤول او ما تمله الارادات المسؤولة او الوساطات وليس الاختيار الذي يعتمد المسيرة الوظيفية للفرد .

\subsection{2 العلاقة بين العمل ومسهاه (عنوان وظيفي)} بدعا لابد من تساؤل: هل يوجد في المؤسسات وظائف بالمعنى الموضوعي اي موصوفة لها واجبات ومسؤوليات محددة وصلاحيات واضحة و لها اسم (عنوان )

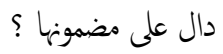
يعتقد الباحثون بان لاتوجد وظائف بالمعنى الفني ولكن يوجد موظفون يقومون

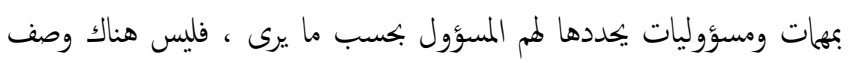
وظيفي بالمعنى الذي مر ـ ذلك ما اظهرته مقابلة عدد من الموظفين ، بان وظيفته بحسب ما كلفهم به المسؤول من واجبات ـ تاسيسا فالوظيفة هي نكليفات قد لا تتكامل وتتسق وتتجانس مشكلة كيانا . تبنى الباحثون هذه التسمية التي تبدو غريبة في الارث الفكري ، لكنها حصيلة

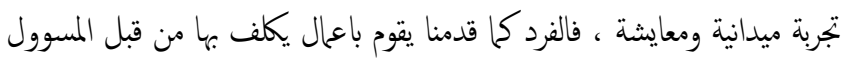
، ومعين بعنوان وظيفي لا ينسجم مع هذه الاعمال ـ لذلك فقد هذا المسمى ( الوظيفة ) معناه ومبناه ، فاسم الوظيفة في الحقيقة دال عليها يفصح عن حماتها ومسؤولياتها وواجباتها وهل هي اشرافية ام لا (*) .فالوظيفة كل متكمل عنوانا 


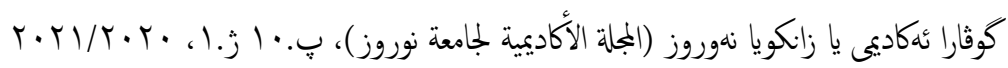

4.7.2عنوانات الوظائف تحدد على اساس مواصفات الفرد لا العمل

ودرجته المالية

اي ان تحديد عنوان وظيفي للفرد يعتمد على تخصصه وعلى درجته المالية : مثلا حصل (13 ) موظف على شهادة الماجستير في الزمن ذاته ، غيرت عنواناتهم الى مدرس مساعد ،ومدرس جامعي ومدرس جامعي اول ، كل حسب الدرجة الوظيفية التي هو فيها ومع اهمال الاشتراطات لشغل

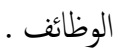

كذلك هنالك من حصل على شهادة من الدراسات المسائية ، فغير عنوانه الوظيفي من م. ملاحظ الى م. متر.م ، ثم الى متر.م.... كذلك من م. ملاحظ فني الى باحث لحصوله على شهادة بكالوريوس في الدراسات الاسلامية وحوار الاديان ... وهذه غيض من فيض ، كل ذلك مع بقاء الموظف في عمله السابق · كل ذلك يؤشر عدم وجود وظائف حقيقية ، انما مسميات وظائف وفاقا لما

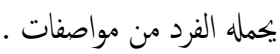
وهذا يعني كم تتحمل الموازنة( بند الرواتب ) من نكاليف عالية لاتكافي العمل المودى لان الراتب يحدد على المؤهلات لاعلى اساس العمل المؤدى ـ.

\subsection{2 تداخل المفاهيم وعدم التمييز بينها}

ليس هناك تمييز بين مفهوم الموظف الفني وغيره ، من المفاهيم اذ يلحظ اعتاد العنوانات الفنية بحسب تقدير المسؤول عن التصنيف فالمهندس فني اين ماكان ، ومعاون الملاحظ الفني ( خريج المعاهد ) مهاكان تخصصه فهو فني (هنا لابد من الاشارة الى ان هذا العنوان يمنح حصرا لخريجي المعاهد الفنية تييزا لم عن خريي الاعدادية ويرفع الى معاون ملاحظ ) فنييز الفني عن غيره هو المسمى الوظيفي ، وليس طبيعة العمل وارتباطه المباشر

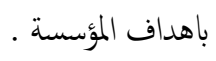

فالفني في الجامعات هو حملة الشهادات الجامعية الاولية او الشهادات الفنية ( خريي المعاهد ) او المهنية العالية او الشهادات الفنية الواردة عنوانتها في رابعا وخامسا وسابعا وثامنا واربعة وعشرين من الجدول 2 الملحق بقانون الملاك ذي الرٍٍ ( 25 ) لسنة 1960 المعدل الذين يمارسون تدريب الطلبة في المختبرات والورش والحقول حصرا ( هيكل عمل الفنيين رقٍ ( 79 )
الاعداد لهذه الموارد البشرية ( الاستثمر في التعليم ) من ناحية اخرى ارتفاع الكلف الادارية وانخفاض انتاجية الاجور والرواتب للوظائف الوهمية مقارنة بانتاجية الاجور والرواتب للوظائف الحقيقية التي يقومون بها . تاسيسا فان ذلك يؤشربهلا ولامبالات مركب من المؤسسة و الوزارة المعنية

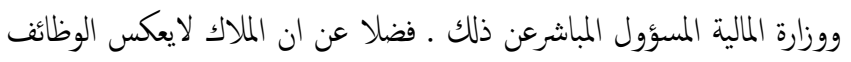

\subsection{2 علاقة تخصص الفرد بالعمل الذي يؤديه} يروى عن الامام علي عليه السلام ، انه قال (العلم مقرون بالعمل, فن علم عمل, والعلم هيتف بالعمل, فان اجابه وال ارتحل عنه), (نهج البلاغة , الحكمة 366) ليس كلام ابلغ من كلام سيد البلغاء ، لقد او جز في بهذه العبارة ـ القاعدة الاساس في العمل ( الشخص المناسب في المكان المناسب ) . ان نجاح الفرد في اداء مهاته يعتمد على مؤهلاته ( الشهادة ، التخصص ، المعارف التي يتلكها ، الحبرة في العمل ، المهارة التي اكتسبها ) وقدراته الادائيه ـ لذايجب ان يسند اليه المهات التي تتناسب وقدراته الادائية ـ غير ان الواقع يظهر غير

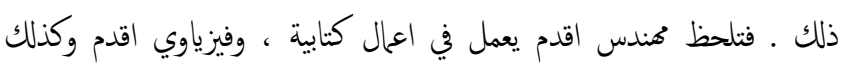
هندس زراعي اقدم يقوم باعمال كتابية ،م. كيمياوي يعمل كاتب في الحسابات ، تخصص تاريخ ، علوم سياسية ، لغة انكليزية يعمل في الحسابات . ان هذا يؤشر ان عنوانات الوظائف تحدد على اساس مواصفات الفرد لا على

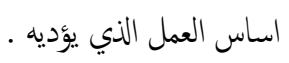

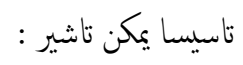
- - م ان عمل الفرد لا يرتبط بمؤهلاته . - الاجر الذي يتقاضه الفرد بينى على اساس عنوانه الوظيفي لا على اساس

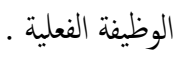
من هو مؤهل لها .

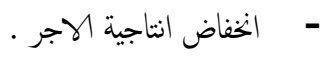

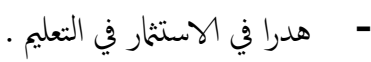
- هدرا في الانفاق الجاري اذ يتقاضى الفرد اجرا اعلى من استحقاقه . 


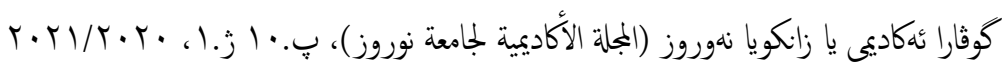

بعامة يباح القول بان الوظيفة ليست ترفا ولا عطية يمنحها المسؤول لمن يشاء ويرغب ، اما هي حاجة يفرضها حجم العمل وطبيعته ، اي انها

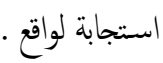
ان تحويل المناصب الى منح وعطايا يوزعها المسؤول بحسب رغبته، ويخذفها ويستحدثها بحسب الرغبة او استجابة لاملاءات خارجية، هي تجاوز على القوانين والانظمة والموارد المالية . بعامة الوظيفة بدرجة هي بدعة سياسية ، فهي وظيفة فرية تمنح لاصحاب الحضوة والمحسوبية وذلك لتبرير المرتب الذي يثقاضونه والمزايا التي يحصلون عليها ـ وبالثالي فهي بدعة لامحل لها في مجال المعرفة الادارية . ومما تجدر الاثارة اليه ان وظيفة رئيس الدائرة بدرجة مدير عام ( رئيس دائرة ) وليس مدير عام لان وظيفة المدير العام تلزم وجود مديرية عامة، لكنهم يوقعون بعنوان مدير عام الدائزة ( س ) لما يحققه هذا المسمى الوظيني من منزلة وهمية ومكانة مؤقتة .

\subsection{2 تغيير العنوان مقابل الترقية}

يحدد ملاك الوظائف التي يتطلها تسيير الاعمال في المؤسسة مدة خطة

$$
\text { المؤسسة (عام او ... ) عددا ونوعا . }
$$

فهو بذلك ياخذ شكلا هرميا ترتب فيه الوظائف بحسب اهميتها ومستوى

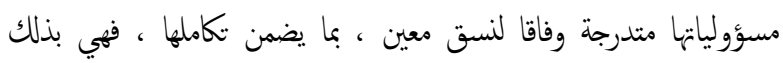
تترتب بنسق ذي تسلسل رئاسي تبعا لمستوى المسؤولية ودرجة صعوبتها . عليه فان الوظائف تتدرج وفاقا لمستويات محددة يقتضيها مستوى الاداء ونوعه وطبيعته في المؤسسة , لقد فرض هذا الندرج ان لكل مستوى وظيفي متطلبات معينة تناسب طبيعة الوظيفة ومستواها ، اي مواصفات محددة خاصة لشاغلها ـ فعلى سبيل التثيل ، على تدرج الوظيفة ، (كاتب ، م.ملاحظ ، ملاحظ ، رئيس ملاحظين ، مدير ..) وهكذا معظم الوظائف ، ان هذا التدرج يفرض مواصفات تتتص بكل مستوى وظيفي ينبغي توافرها فيمن يشغلها ، والانتقال من وظيفة الى اخرى ذات مستوى اعلى يستلزم توافر شروط شغلها في الموظف ، فضلا عن شروط اخرى ، وجود وظيفة شاغرة ، او حالة جديدة تحققت ، استحداث وظيفة جديدة لحالة طارئة . هنا يثار تساؤل يستوقف الباحث هل مسميات الوظائف ترتبط بضمونها؟، ام انها تسمية وحسب ؟ ان الاجابة على ذلك ثقتضي تحليل
لقد حمل هذا التداخل بند الرواتب والخمصصات اعباء مالية كبرى بسبب الجهل في التمييز بين الفني وغيره من العاملين الامر الذي ينعكس هدرا في الموارد البشرية والموارد المالية ( الرواتب العالية مقارنة بالاداء ) .

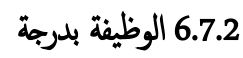

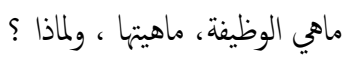
اوضح البحث في سابق الصفحات ، ماهية الوظيفة ، ومبررات استحداثها . اذ يؤكد التزاث الفكري المتصل بالموارد البشرية ان الوظيفة مسألة تفرضها طبيعة العمل وحاجته فهي تتشكل من حمات ومسؤوليات وواجبات، فهي بالتالي اعباء نبؤ بها كهل الموظف الذي يشغلها. فهي بالتالي استجابة موضوعية لا ذاتية . بعد ذلك ماهي الدرجة الوظيفية ؟ ان الوظائف في الملاك تتوزع في مستويات متباينة تدرج بحسب اهيتها وجيم المهات واهميها والمسؤوليات وحجمها وعبء العمل ، اذ توضع كل بموعة وظائف ضمن درجة معينة . ومما لاشك فيه فان كل مستوى وظيفي ( درجة) يقابلها مستوى مواز لها درجة مالية تحدد الحد ين الادنى والاعلى لاجر الوظيفة اذن من هو الموظف بدرجة ، هو موظف بدرجة دنيا في سلم الوظائف ، يعين بدرجة اعلى من المستوى الحتيقي لوظيفته ـ بالتالي فهي بدعة سياسية لاعل لها في المعرفة التنظيمة ، ذلك لمنح مزايا الدرجة الاعلى .

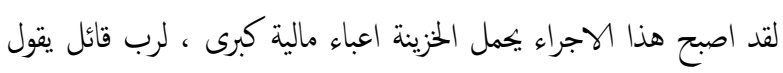
ان هذا لم يكن بدعة جديدة ، فهي كانت سائدة فيا سبق ! اجابة ذلك ان درجة مدير عام هي ضمن الدرجات الوظيفية العامة ولايتزتب عليها اية اعباء

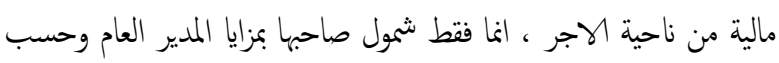
، فلا تغيير في الدرجة ولا زيادة في الراتب . لماذا موظف بدرجة مدير عام ، ذلك لان المدير عام منصب تفرضه طبيعة عمل المؤسسة وحجم العمل فهيا ، فالمديرية العامة تقضي طبيعة العمل فيها منصب مدير عام ـ بل لم يكتفوا بذلك ولكنهم تعدوه المى تعيين معاون مدير عام وهو منصب غير مبرر ، فضلا عن عدم جواز ذلك واقعا وقانونا ـ بل تجاوزوا ذلك المى التعيين على منصب موظف بدرجة مدير عام المى تعيين موظفين ليس لهم من الخدمة مايؤهلهم لشغل هذه الدرجة فنهم من له خدمة

$$
\text { لاتزيد عن خس سنوات . }
$$




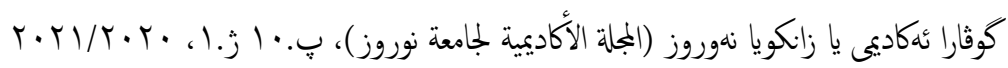

تعد الوظائف اداة المؤسسة ووسيلتها الاساس في تحقيق اهدافها ذلك من خلال تكامل اداءها مجتمعة, لذلك تتنوع الوظائف المطلوبة وتتباين من مؤسسة الى اخرى تبعا لاهداف المؤسسة ـ الامر الذي يفرض اشتقاق الوظائف من هذه الاهداف , لذالك تأت منسجمة ومتسقة معها تعكس طبيعة الاعمال في المؤسسة ـ فالقاء نظرة على الوظائف تعطي انطباءا عن اهدافها الموسسة وطبيعة ومجال اعلالها كنها مشتقة منها. وهذه الوظائف لها مسميات مشتقة من طبيعة مهاتها ومسؤلياتها وواجباتها ومتسقة معها ، مصاغة على وزن اسم الفاعل للدلالة على القيام بالعمل (كاتب ، ملاحظ ، مدير ، محاسب .....) مسمى الوظيفة (عنوانها ) وهماتها دال ومدلول عليه.

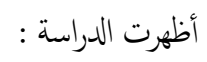

- عدم توافق مسميات الوظائف الواردة في الملاك مع طبيعة نشاط المؤسسة

\section{- عدم توافق مسمى الوظيفة وطبيعة هماتها ومسؤولياتها .}

- عدم توافق الراتب الذي يتقاضاه الموظف مع طبيعة هماته ومسؤولياته . تاسيسا تؤشر الدراسة عدم توافق بين هرم الوظائف وهرم الموارد البشرية وهرم

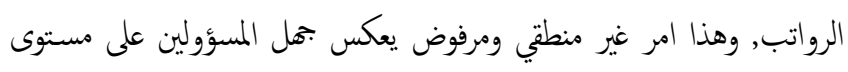
المؤوسسة ووزارة المالية او لامبالات فهو تخريب متعمد وفساد كبير يعكس :

$$
\begin{aligned}
& \text { - } \\
& \text { - هدرا ماليا ( رواتب فوق الاستحقاق ) . } \\
& \text { - م ت تدنيا في اداء الموارد البشرية . } \\
& \text { - - هدرا في الاستثمار في التعليم }
\end{aligned}
$$

فالوظائف تصاغ وفاقا لمصالح الافراد ومواصفاتهم لاعلى اساس العمل الذي يؤدونه، اي تجريد المسمى الوظيفي من معناه ومبتغاه . ذلك على حساب مصلحة الجمتع . فتحديد الوظائف الظاهرة في الملاك لايستند الى الواقع الامر الذي يكشف درجة الحيانة في اداء الواجب من قبل المسؤولين . لقد نجم ذلك بسبب سوء اختيار المسؤولين القائم على اسس غير موضوعية الامر الذي يجعل من الاختيار للوظائف القيادية مكرمات وعطايا توزع على اساس المحسوبية، يمنحها الرئيس على اسس غير موضوعية فاسندت الوظائف
مسميات الوظائف وكيف استحدث ـ ان اسم الوظيفة مصاغ على وزن اسم الفاعل ، ذلك للدلاله على من يقوم بالعمل ( الموظف ) وهي ليست عشوائية، انما هي مشتقة من طبيعة العمل وتدل دلالة مباشرة على مضمون الوظيفة، اذن هي ليست مطلقة ، انما محددة بههات محددة ومسؤوليات معينة . فهي بذلك مشتقة من طبيعة الوظيفة ومكتواها ومستواها في هرم الوظائف ، هذا يعني ان الوظيفة كيان كلي لاينفك بعضه عن بعض ، مسىى، همات، مسؤوليات، واجبات ، صلاحيات ، مواصفات شاغلها . ولو كان ذلك غير ذلك لاتجه المشرع والمبراء الى اعتمد الدرجة دون الوظيفة، اي موظف بدرجة س ، وكنى ـ ان اعتاد مواصفات خاصة لكل وظيفة، اوجب تقييم الموظف سنويا بموضوعية وعناية ودقة لانها تمثل سيرة الموظف خلال مدة التقييم السنوي ( علاوة ) لانها تعد بمثابة تحديد مواصفاته الجديدة بعد سنة ،بمعى ان الزيادة السنوية توازي التغير الحاصل في مواصفاته ولتكون الزيادة السنوية حافزا لتقدم الموظف ، لا كما هي الان روتينية مما افقد التقييم السنوي غايته ومبتغاه ، وان هذا الاسلوب يعد خيانة للواجب وفسادا واهدارا للمال العام ،ذلك يمنح الزيادة السنوية لمن لا يستحقها ، فضلا عن قتل الحافز الذي يدفع الموظف للاجتهاد والتطور . اذن الزيادة السنوية هي قيمة الاجتهاد والتطور في الاداء ـ تاسيسا فان مسالة تغيير العنوانات الوظيفية التي اضحت سمة الادارة اليوم افقد الوظيفة

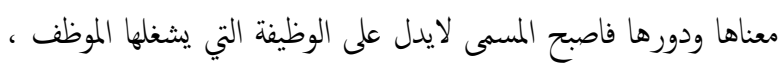
كل ذلك لالشي ال لمسألة معنوية واعتبارية فارغة غير حقيقية . ان الترقية هي الانتقال من وظيفة الى اخرى ذات محات ومسؤوليات اعلى، يجب ان تخضع لقيود ليست عشوائية او تخضع لرغبات الموظف ـ ان استشراء هذا الامر جعل من الوظائف الظاهرة في الملاك مسميات وحسب ، فضلا عن ان هذا الاجراء يؤدي الى رفع كلة العمل ، ورفع كلفة المنتج سلعة او خدمة ـ وهو امر لايستقيم والمنطق لان ذلك يؤدي بالتالي الى الارتفاع المستمر بكلة الانتاج ـ فالاساس في التزقية هو وجود وظيفة شاغرة، والاختيار يخضع للمنافسة لتحديدالافضل لشغلها . يتضح من ذلك مقدار مائثله هذا الاجراء من هدر في المال العام ، وفسادا كيرا .

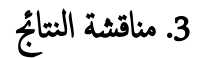




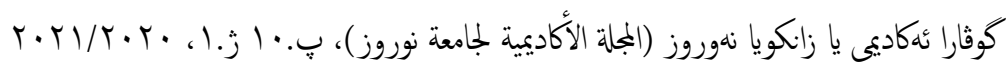

روى لي احد الاصدقاء عن حالة مرة به واثارة استغرابه لعدم منطقيتها عندما كان وكيل عميد كلية الحقوق في جامعة النهرين ، اذ جاءه شخص يحمل امرا جامعيا لتعيينه (استاذ)وبلقب علمي (مدرس مساعد) كونه حاصل على شهادة الماجستير, وكان يعمل في خارج العراق وبحجة انه متضرر سياسي ، جُرى تحديد وظيفة له على مقاساته ، اي الوظيفة المجزية للمدة التي قضاها في الخارج، فجرى تعينه بوظيفة استاذ وبلقب علمي (مدرس مساعد) وهذه اول مرة تجري فيها عملة الفصل بين اللقب العلمي ( الذي هو درجة وظيفية ولقب علمي ) وبين الوظيفة استاذا التي هي (لقب علمي) اولا ووظيفي ثانيا ، ولاييوز شغلها الا لمن يستحقها ,فهي

$$
\text { استحقاق علمي اولا ووظيفي ثانيا . }
$$

لكن المسؤول في الوزارة لم يستفسر من وزارة التعليم العالي والبحث ترث العلمي التي هي جحة الاقتاء في هكذا حالات ولا ادري لماذا لم لجأ المى وزارة المالية والتي قطعا ستجيب بانها درجة وظيفية . لقد احدث هذا الفصل اثرا ماليا لايستحقه من يحمله فكما هو معلوم ان الراتب للوظيفة التي لها اعباء وهمات ومسؤوليات حدد الراتب على اساسها اي على اساس ادائها وليس على اساس مقاسات الفرد الافتراضية لان امكاناته ومستوى ادائه لايصل الى مسمى الوظيفة ـ ان السبب في ذلك هو الفصل بين المسمى الوظيفي ومايؤديه الفرد ، اذ يمنح المسمى الوظيفي استنادا الى مقاسات الفرد ، والذي يعد خرقا للاعراف والسياقات والاظظمة والتعليات والقوانين خدمة للافراد ( مصلحة خاصة واضرارا بالدولة ، المصلحة العامة ) لندني مستوى

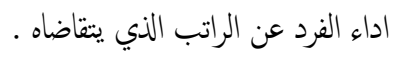

لقد ادى ذلك الى الفصل بين مسمى الوظيفة واللقب العلمي الذي هو وظيفة ولقب علمي في الوقت ذاته وهو يمثل اعباء وهمات محددة ، فترى الموظف يقول لك انا درجتي استاذ او استاذ مساعد واذا ماسالته متى حصلت على الترقية يقول انا مدرس لقبا علميا، لكني استاذ درجة وظيفية، وهذا هو المضحك المبكي كما يقال .

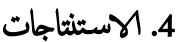

تخضت مناقشة ننائُ البحث عن تاشير الاستنتاجات الاتية : الوظيفة ليست ترفا ، انما هي حاجة يفرضها واقع الحال وطبيعة العمل ،

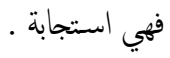

فالمنطق يفرض ان يستند الاختيار للوظائف الى السيرة الذاتية للفرد والتي تعد بوابة العبور الى الوظيفة من خلال ما تحويه من تقارير الخبرات وتقارير الاداء، وكلما اعدت السيرة الذاتية بدقة وموضوعية ، جعلت الاختيار سليا وموضوعيا. فالوظيفة استحقاق وليست منح او تكريمات وعطايا الامر الذي انعكس تدنيا في الاداء وتدميرا للمؤسسة ،ضضلا عن ذلك فقد نجم عنه : - م لم تعد الوظيفة حافزا لتقدم الموظف في الوداء. - اهرة المشاغبات من اجل الحصول على الوظيفة . - - مالتنافس غير المشروع للحصول على الوظيفة . - ل م تعد الوظيفة استحقاق بل اصبحت منحا وعطايا . - تغيي عنوانات الوظائف بحسب المقاسات . من المعلوم ان الفتيا تؤخذ من مصدرها ، اذن فهي تخصص فلا يجوز اللجوء الى مفتي غير متص بنتوى من اختصاص بحة اخرى . فني الشؤون الوظيفية المقتي وزارة المالية ، وفي الاختصاص العلمي (مسألة فنية) فتختص بها وزارة التعليم العالي والبحث العلمي. فينا يكون على رأس مسؤولية (جمازا فليس هناك مسؤول لغياب المحاسبة) اما جاهلا او قاصدا مستغلا في عدم المام او معرفة العاملين في المؤسسة النعلمية . هن المعروف ان الوظائف العلمية بما تحتويه من القاب علمية ، لاشك ان المشروع وضعها على اساس وصف وظيفي ومواصفات لمن يشغلها ، فضلا عن انها محفز للعاملين. لكن ما يحدث في وزارة التعليم العالي والبحث العلمي بسبب فتوى استغلها احد المسؤولين في الوزارة مستفسرا من وزارة المالية هل المسميات ( مدرس مساعد، مدرس، استاذ مساعد، استاذ)، هي درجات، وهو يتوقع ان اجابة الوزارة ستكون نعم هي درجات وظيفية اي ان المشرع دمج بين الدرجتين العلمية والوظيفية، وذلك لتكون حقا لمن يستحقها ومحفزا لدفع العاملين بالاجتهاد لنيلها. لكن مككن ان يحصل هذا عندما يتولى اعلى مسؤولية ادارية ولمسوبية انتائية او سياسية او محاصصية شخص لاينتي الى التعليم العالي انما جاءه نقلا من مؤسسة اخرى فهو اما ييهل او يتجاهل ، ذلك انه بعيد عن هذه المؤسسة وليس وليدها الذي يعرف اعرافها وتقاليدها وسياقاتها فيتجاوز او يقزز على القوانين والاعراف فقد سيطر في مرحلة ما اعلى مسؤول اداري ومعاونه من

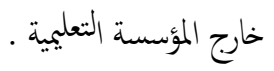




$$
\begin{aligned}
& \text { O } \\
& \text { مراحل التعيين : }
\end{aligned}
$$

أ. اجر يوي وهذه مخالفة فالاجر اليومي هوللاعمال الطارئة والاستثنائية تحمل على الميزانية التشغيلية دون بند الرواتب

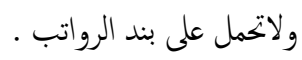

ب. العقد هذه مخالفة اخرى اذ العقد هو لعمل موسمي او عمل مؤقت غير مستمر بيبن في العقد مدة العقد وطبيعة العمل كذلك تتحمل به

$$
\text { الميزانية التشغيلية ولايتحمله بند الرواتب . }
$$

ج·وظيفة على الملاك اي ان الفرد ينتقل عبر هذه المراحل يستند على

$$
\text { المحسوبية والوساطات والقرابة }
$$

هذه الاجراءات تؤشر تجاوزات اساسها الجهل والتسيب والاههال واشغال الوظائف في اقسام الموارد البشرية والمالية بافراد لايمتلكون المعارف

$$
\text { والخبرات اللازمة . }
$$

عنوانات الوظائف الظاهرة في الملاك لاتوائم بينها وبين طبيعة ومجال عمل المؤسسة التعليمية ( طبيب ، صيدلي ، مهندس ... الخ ) ومشتقانها نزولا وصعودا، فطبيعة عمل المؤسسة تعليمي بحت ، كما الحال مع المدارس فالمدرس هو العنوان الوظيفي السائد فيها ولا علاقة له بالتخصص ، بيولوجي ، كيمياوي...... الى غير ذلك من التخصصات ـ هذا يؤشر ان المسمى الوظيفي لاعلاقة له بالعمل الذي يمارسه الموظف انما علاقته بتخصصه وبما يجقق له راتبا اعلى . فضلا عن ذلك لو راجعت ملاك الوزارة لوجدت عنوانات الوظائف تدريسيه : ( استاذ ، استاذ مساعد ، مدرس ، مدرس مساعد ) في حين انها لاتتجاوز ان تكون وظائف ادارية ليس اكثر ـ كذلك نجد وظيفة مدير عام وهي لاتتجاوز وظيفة رئس قسم ، اذ ليس هناك مديرية عامة في الوزارة ، وهي بدعة مانزل بها الفكر الاداري من سلطان ولااذن بذلك . تاسيسا يؤشر ذلك عدم وجود وظيفة بالمعنى الموضوعي السليم فهي عبارة عن كيان متنافر لاتناغخ ولاتجانس بين حماتها . ان اشتغال اشخاص بتخصصات لاتتوافق مع ما يمارسون من عمل يخالف الفقرة رابعا من تعليمات الملاك عدد 23 لسنة 1973 .
ان مسمى الوظيفة ( عنواناتها ) مشتق من مجال عمل المؤوسسة ، ويعكس هحات ومسؤوليات الوظيفة ـ فالعنوان لاينفصل عن الوظيفة . الوظائف بدرجة هي وظائف وهمية غير حقيقية فهي ليست سوى منح وانعامات تمح لذوي الحظوة والمحسوبية ، فضلا عن ذلك فان كحاتها ومسؤولياتها لاتوازي الاجر المتزتب عليها. فالراتب اعلى من استحقاقها ، فهي لاتعدو ان تكون اكثز من قسم ·

الملاك هو عدد ونوع الوظائف التي يتطلبها العمل في المؤوسسة خلال السنة موزع على مستوى الاقسام والشعب والوحدات بمعنى ان لكل قسم وشعبة ووحدة ملاكه الخاص . لذلك فالملاك متغير سنويا من حيث

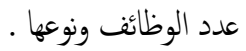
يترتب على ذلك ان الوظائف مرتبطة بالتشكيل الذي نتبع له ولاعلاقة لها بشاغلها ، اي هي ثابتة في تشكيلها لاتنتقل بانتقال شاغلها . الوظيفة كل متككل متجانس لاينفصل بعضه عن بعض اسم ( عنوان )

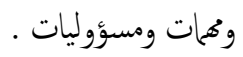
تظهر الملاكات عنوانات وظائف فتط وليست وظائف حقيقية يقتبها تسيير الاعحال في المؤوسسة فهي مسميات غير حقيقية . هناك عاملون اخرون لا تظهر وظائهم في الملاك فهم يعملون تحت مظلة اجر يومي وهذه مخالفة فالاجر اليومي هو لانجاز محمات محددة مثل عمليات حفر او تاسيسات صهية او غير ذلك ، تضاف اجورهم الى كلف انجاز الاعهال . تنهي علاقته بانجاز المهات غير ان الواقع غير ذلك فهم مستمرون · ويعملون في وظائف ادارية او فنية.... كذلك هناك تخريج اخر اذ يغير هولاء العاملين باجر يوي المى عاملين بعقود وهذه ايضا مخالفة اخرى اذ العاملين بعقود يجب ان يتضمن العقد العمل الذي يتعاقدون على انجازه ومدة الانجاز تنهيي عقودهم بانتهاء المدة . وهذا يعد مخالفة قانونية تعكس ضعف الموظفين المسؤولين عن ذلك في الشؤون القانونية والمالية والموارد البشرية فضلا عن ضعف وجز الاجهزة الرقابية . ترتب على ذلك ان العاملين في المؤسسة ينقسمون الى : O موظفون على الملاكك O 


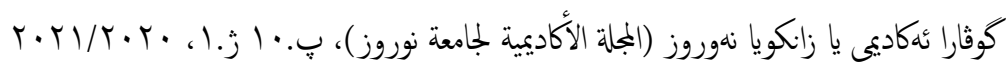

موظفون كنيون من الطراز الاول لعلمهم بخبايا الاداء ومكمن الخطا والزلل وسوء التصرف او سوء الاداء المقصود الذي يعكس فسادا .

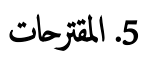

تاسيسا على ما افرزته مناقشات النتاجُُ يمكن اعتاد المقترحات الاتية لمعالجة الخللل:

تحديد ملاك موضوعي المؤسسة وفاقا للاتي:

O تحديد الوظائف المنسجمة مع طبيعة وبجال عمل المؤسسة وتغير العنوانات الواردة في الملاك وفاقا لذلك . - ملك

O تحديد عنوانات الوظائف موضوعيا بجيث تتلائم مع المهات والمسؤوليات والواجبات المؤدات ، لابما يوافق مؤهلات الموظف .

O وضع الملاك على مستوى التشكيلات الادارية اي لكل تشكيل اداري ملاك ثابت عددا ونوعا مثلا : المالية ، الافراد ...........

O الوظائف ثابتة في ملاك التشكيل ولاعلاقة لها بشاغلها(فهي تشكيل مستقل عن شاغلها يتضمن كمات وواجبات ومسوليات ترتبط بالتقسيم الاداري التي هي فيه) ، اي في حالة نقله ينقل بدرجته

$$
\text { وليس بوظيفته . }
$$

O العمل على الموائمة بين الوظيفة الحتيقية عنوانا وراتبا ومؤهلات شاغالها .

O اعادة توزيع العاملين لما سيفرزه انجاز الخطوات اعلاه بحسب

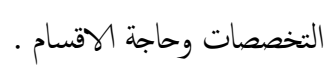

اعادة النظر بقانون الرواتب وعدم اعتاد مستوى الشهادة في تحديد الراتب ، وربط الراتب بالوظيفة لابمستوى الشهادة ، وتحديد وظائف ودرجات محددة لكل مستوى شهادة ـ اي الغاء تحديد الرواتب بحسب الشهادات للوظيفة الواحدة ، وهذا امر مخالف للمنطق فالراتب للعمل وليس للشهادة اي تحديد سقف ( درجة محددة ) لكل مستوى شهادة ، مثلا الشهادة الاعدادية لاتتجاوز الدرجة الخامسة ، الدبلوم لاتتجاوز الرابعة،

$$
\text { البكالوريوس لاتتجاوز الثالثة وهكذا . }
$$

اعتماد القاعدة الراتب للوظيفة ( اي المهات والمسؤوليات والاعباء التي يتحملها الموظف ) وليس للموظف - اي لايحدد الراتب على اساس مؤهلات الموظف انما على اساس الوظيفة المؤداة .
كذلك فان اشغال وظائف ادارية من قبل تدريسين خخالف للفقرة اولا من

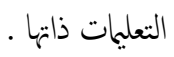

بطالة هيكلية بسبب عدم الافادة من التخصصات وتعينه بوظائف لاعلاقة له لها بتخصاتهم

الوظائف هي منح وهبات للافراد بحسب مؤهلاتهم وتخصصاتهم لابحسب المهات التي يؤدونها ومبا يحقق لم اجر او مخصصات تناسب مؤهلاتهم . ان الهيكل التنظيمي لايعكس الواقع الحقيتي والموضوعي كونه يحتوي وظائف لاعلاقة لها بمجال عمل المؤسسة فضلا عن انها لاتعكس المهات الحتيقية للوظائف الظاهرة فيه .

هدرا في الموارد البشرية، فضلا عن الهدر المالي الذي ترتب على الملاك الرسمي الذي لايعكس الملاك الموضوع ـ الذي نجم عن هدرا ماليا وبشريا .. اسناد المسؤوليات القيادية لافراد عديمي الكفاية لايمتلكون القدرات الوزمة لاشغال هذه المناصب من خبرات ومعارات يتطلهيا شغل هذه المناصب . لايوجد ملاك على مستوى التشغيلات الادارية ، قسم ، شعبة ، وحدة . اي ان لكل تشكيل اداري ملاك خاص ثابت . المسمى الوظيفي يرتبط بالموظف ولايرتبط بالوحدة التنظيمة . فصل التقييم السنوي عن نوعية الاداء وعده مسالة روتينية لاهمية له سوى انه لمنح العلاوة او التزفيع جهلا باهيته وأنه الاساس في زيادة الراتب فضلا عن ان الاساس في الاختيار للوظائف الهرق وللوظائف القيادية . فصل الترقية عن الوظيفة ، وعدها فقط زيادة في الراتب ، اي الفصل بين التزيع والتزقية ، والاصل انها مرتبطان ، فلا ترفيع دون تغيير العمل والمهات المى مهات اعلى . غياب الاساس الموضوعي لبناء وتحديد الملاك واعتماد الاساس المالي في بناء الملاك بسبب الابتعاد عن ربط محتوى الوظيفة الذي يؤديه الموظف وعنوان الوظيفة الظاهرة في الملاكك. مما زاد هذه الاخطاء استحكما ، ضعف الوجهزة الرقابية النابم عن عدم خبرتها بسبب التعيين المباشرفي هذه الاجهزة في حين يجب ان يتم اختيار موظفي الرقابة من الموظفين ذوي الخبرة والاداء المميزوالمشهود لم بانهم 


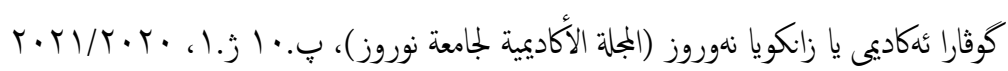

فالعنوانات الندريسية ليست وظائف عامة، كما فسرتها الدائرة الادارية لمعالجة حالات خاصة، فهي معالجة غير موضوعية .

اعداد دراسة لواقع الوظائف وتحديدها بحسب الحاجة الفعلية وبالمسميات الوظيفية الملائمة لمجالات العمل دون النظر لمن يشغلها ومواصفاته . دراسة واقع الموارد البشرية واعادة توزيعها بحسب الوظائف الملائمة والحاجة الموضوعية ونقل الفائض عن الحاجة . 13- اعداد الملاك بحسب حاجة المؤسسة الفعلية السنوية اي ان يعد الملاك على اساس تغير الاهداف سنويا ـ ونقل الفائض . اعتماد القوانين النافذة فيا يتصل بالعاملين باجر اذ ان الاجر هو عمل طارئ ، مؤقت لمدة زمنية قصيرة وكذا الحال فيا تتصل بالعاملين بالعقود ، اذ ان العقود يجب ان يحدد فيها العمل المطلوب والمدة اللازمة لانجازة فليس هناك عامل باجر لمدة غير محددة وكذلك العقد . كل ذلك يؤشر ضعف الاجهزة الرقابية المركزية او عدم اهتماها اله بالجانب المالي وحسب. هذا يفرض دع هذه الاجمزة الرقابية بالكفايات الفائقة باختيارهم من العاملين المائزين في الدوائز ونقلهم الى ديوان الرقابة المالية واعادة تاهيلهم ـ اذ ان المدقق يجب ان يكون محاسبا من الطراز الاول

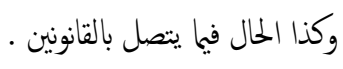
توجيه العاملين في اجهزة الرقابة المركزية بان لايكون تركيزم على الجانب المالي اذ ان جانب الموارد البشرية يترتب عليه هدرا في الموارد البشرية فضلا عن ان ذلك ينعكس ايضا هدرا ماليا لما يتقاضوه هؤلاء من رواتب . حذف وظيفة مدرس مساعد من الوظائف الثدريسية واعادة استحداث وظيفة معيد بدلا عنها وحصر التعيين فيها لملة الماجستير. تشكيل لجنة مختصة لدراسة الاشكلات التي احدثا اعتبار الالقاب العلمية وظائف عامة في حين هي القاب علمية ووظيفية في ان واحد ولا يكن

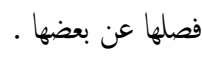
19- اعتماد هيكل عمل الفنيين في وزارة التعليم العالي والبحث العلمي ذي الرق (79) لسنة 1994 المحدد فيه الفنيين , دون الاعتماد على الاجتهاد

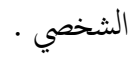

تعديل عنوان الموظف بدرجة الى الوظيفة بدرجة الى الوظيفة الحتيقية التي يؤديها مدير دائزة ، رئيس قسم اذ ان هذه ليست وظيفة وانما أنغام او هبة

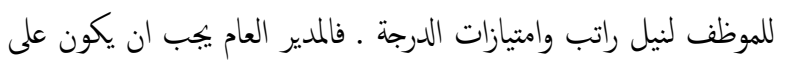
راس مديرية عامة . الفصل بين الموظف والوظيفة التي يؤديها فالوظيفة ترتبط بالتشكيل الاداري لاتنفصل عنه- اي في حالة نقل الموظف الى وظيفة اخرى ينقل

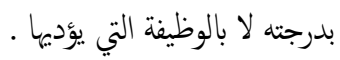
اعتماد السيرة الوظيفية ( الاضبارة الشخصية ) اساسا في الترقية او

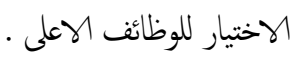
الزام المسؤولين باعتاد اداء الموظف ومسيرته خلال مدة التقويم عند اعداد الثقويم السنوي للموظف وان يكون التقويم موضوعيا وجادا بحسب استحقاق الموظف ، لان هذا التقويم يترتب عليه :

$$
\text { O زيادة في الراتب ( علاوة ) . }
$$

اذا"هذا التقويم يعد اساس للاختيار للوظيفة الاعلى اي ان التزقية هي استحقاق وليس حق. دراسة واقع حملة الشهادات العليا ونقلهم الى وظائف تدريسية ، وعدم تشغيلهم في وظائف ادارية كما هو الحال في الجامعة والوزارة اذ يتزتب على ذلك : - 2 O مجز فرص وظيفة O رواتب اعلى لاتتوافق والعمل المؤدى O تعطيل طاقات يجب استغلالها في مواقعها الحقيقية O مخالفة للقوانين والتعليمات النافذة (الفقرة اولا من تعليمات الملاك 23 لسنة 1973 ) تحديد الاجازات الدراسية بالدرجات الدنيا مثل السادسة . عدم اعطاء عنوانات تدريسية وفاقا للدرجة الوظيفية للموظف، اذ ان عنوان الوظائف التدريسية لا ترتبط بقدرات الموظف ومؤهلاته وحسب وانما بطبيعة العمل الذي يوديه ومكان العمل وليس لمعالجة حالثه، 


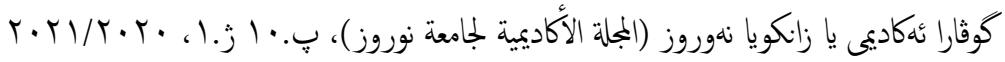
1. سالم سليمان الصابر ، 1999 ، واقع وصف الوظائف في العراق ، تنمية الرافدين ، كلية

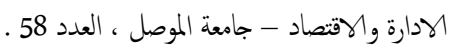

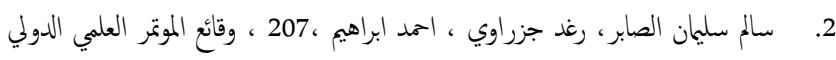

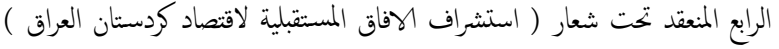
كلية الادارة والاقتصاد ، جامعة نوروز ، للمدة 12-13 نيسان 2017 . 2013

3. www., 2016, Business Dictionary , p.14..

$$
\text { 4. - نهج البلاغة , شرح نهج البلاغة لابن ابي الحديد . }
$$

